\title{
Management of Dyslipidemia in Type 2 Diabetic Patient: A Case Report
}

Danish Mahmood

Department of Pharmacology \& Toxicology, Unaizah College of Pharmacy, Qassim University, Al-Qassim, Saudi Arabia

\section{Abstract}

Diabetic dyslipidemia is characterised by high plasma triglycerides (TG), low high-density lipoprotein cholesterol (HDL-C) and increased small dense low-density lipoprotein cholesterol (LDL-C) particles. Obesity, poor glycaemic control, high fat low fibre diet, and smoking increase the risk of dyslipidemia in type 2 diabetes. Our report presents effective management of dyslipidemia in type 2 diabetics with lifestyle modifications and strict adherence to pharmacological interventions.

\section{Introduction}

Dyslipidemia, one of the major cardiovascular modifiable risk factors, is characterized by high levels of plasma triglycerides (TG) and small dense low-density lipoprotein cholesterol (LDL-C) particles, and low levels of high-density lipoprotein cholesterol (HDL-C) and insulin resistance [1]. It increases the risk of macrovascular and microvascular complications in type 2 diabetes [2].

We present here a case report of effective management of dyslipidemia in a type 2 diabetic with lifestyle modifications and strict adherence to pharmacological treatments.

\section{Case Presentation}

A 60-year old man with recent-onset type 2 diabetes mellitus visited a tertiary care hospital in India. He weighed $80 \mathrm{~kg}$ with 5'9" in height and has a body mass index of $26 \mathrm{~kg} / \mathrm{m} 2$ and hypertension as $140 / 90 \mathrm{~mm} \mathrm{Hg}$. He had a sedentary lifestyle, mild polyphagia, and presented with nonspecific complaints of fatigue and lack of general sense of well-being. The patient had strong positive family history of cardiovascular diseases (CVD), his father had myocardial infarction (MI) which proved to be fatal, mother and elder sister had type 2 diabetes and younger brother had an ischemic stroke 5 years ago. The patient's lungs were clear to auscultate bilaterally, abdomen was soft with minimal diffuse thrombotic thrombocytopenia purpura, no rebound, and no guarding. No bruits were detected on auscultation. Laboratory reports showed HDL-C levels as $40 \mathrm{mg} / \mathrm{dL}$, LDL- as 125 $\mathrm{mg} / \mathrm{dL}$, TG as $140 \mathrm{mg} / \mathrm{dL}$, fasting blood glucose as $104 \mathrm{mg} / \mathrm{dL}$, and glycated haemoglobin $(\mathrm{HbAlC})$ as $8 \%$. Whereas, the normal range HDL-C, LDL, TG, fasting blood glucose and $\mathrm{HbAlC}$ were $\geq 35 \mathrm{mg} /$ $\mathrm{dL}, 65-180 \mathrm{mg} / \mathrm{dl},<150 \mathrm{mg} / \mathrm{dL}, 60-110 \mathrm{mg} / \mathrm{dl}$, and $\leq 5.4 \%$. Patient was taking metformin plus atorvastatin $(500 \mathrm{mg}+10 \mathrm{mg}$, once daily) for past 3 months but had poor adherence to treatment. After strict adherence to the prescribed treatment (metformin and atorvastatin) and lifestyle modifications, his HbA1C level improved to $7 \%$ and LDL-C dropped to $73 \mathrm{mg} / \mathrm{dL}$ at 3-month follow-up. However, there was no significant improvement in HDL-C and TG levels after initiation of atorvastatin. During treatment, the clinician increased the atorvastatin dose to $80 \mathrm{mg} /$ day which further reduced LDL-C level. The high atorvastatin dose was well-tolerated by the patient with no elevations of alanine/aspartate aminotransferase. At 6-month follow-up, the LDL-C level again rose to $85 \mathrm{mg} / \mathrm{dL}$, which was found to be due to suboptimal compliance with the treatment.

\section{Discussion}

The present case report highlights how life style modification and strict adherence to treatment can effectively manage diabetic dyslipidemia in type 2 diabetes. improved. an AMPK dependent pathway[8,9]. org/10.15344/2455-2356/2015/104 original author and source are credited.

\section{Publication History:}

Received: March 12, 2015 Accepted: April 09, 2015

Published: April 11, 2015

\section{Keywords:}

Dyslipidemi, Type 2 Diabetes

Lifestyle changes, including increased physical activity and dietary modifications remains the cornerstone of management of atherogenic dyslipidemia in type 2 diabetes [3-5]. In our report, when the lifestyle of the patient was modified and he strictly adhered to the treatment as suggested by the physician, his HbAlc and LDL-C levels significantly

Our findings are in concordance with earlier reported literature where intensive lifestyle interventions yielded better long-term impact on cardiovascular morbidity and mortality in overweight patients with type 2 diabetes than standard diabetes support and education programs [6]. Similarly, stepwise introduction of lifestyle modification with pharmacologic interventions helped to reduce the risk of deaths (53\%) due to CVD, nonfatal MI, percutaneous coronary interventions, nonfatal stroke, and coronary artery bypass grafting in patients with type 2 diabetes and microalbuminuria [7]. Metformin is most prescribed oral antidiabetic agent. The efficacy, security profile, beneficial cardio-vascular and metabolic effects, and capacity to be associated with other antidiabetic agents makes it a drug of choice for glucose lowering in treating patients with type 2 diabetes. Metformin acts primarily at the hepatic cells by two mechanisms. First, it reduces glucose output and, secondly, augments glucose uptake in the peripheral tissues, chiefly muscle. It reduces hepatic production of generation of glucose from non-carbohydrate carbon sources through

Statins, the lipid-lowering therapy, is the recommended initial pharmacological treatment for lowering LDL-C levels in "very high risk" and "high-risk" categories of type 2 diabetes. Atorvastatin is one of the most worldwide prescribed statins which inhibit 3-hydroxy3-methyl-glutaryl Coenzyme A reductase, an enzyme of the hepatic cholesterol biosynthesis pathway, and reduces low LDL-C associated with cardiovascular mortality and morbidity. Atorvastatin improves the lipoprotein profile and oxidative status in patients with type 2 diabetic dyslipidemia.The beneficial effect of atorvastatin is also attributed to inhibition of inflammatory pathways and peroxisome proliferator activated receptor- $\alpha$ activation[10].

We also suggested atorvastatin in combination with metformin to our patient. After the use of atorvastatin, his LDL-C significantly

*Corresponding Author: Danish Mahmood, Unaizah College of Pharmacy, Department of Pharmacology \& Toxicology, Qassim University, Al-Qassim, Saudi Arabia, Tel: +966-594016751; E-mail: ma.alam@qu.edu.sa

Citation: Mahmood D (2015) Management of Dyslipidemia in Type 2 Diabetic Patient: A Case Report. Int J Clin Case Stud 1: 104. doi: http://dx.doi.

Copyright: (c) 2015 Mahood et al. This is an open-access article distributed under the terms of the Creative Commons Attribution License, which permits unrestricted use, distribution, and reproduction in any medium, provided the 
reduced and with subsequent higher dose of atorvastatin $(80 \mathrm{mg} /$ day $)$ his LDL-Clevels further decreased with no adverse events. The diabetes atorvastatin lipid intervention (DALI) study have reported that either 10 or $80 \mathrm{mg}$ of atorvastatin is equally effective in the treatment of diabetic dyslipidemia [11]. In 2008, Balasubramanian et al in a study on Indian patients assessed the efficacy, safety and tolerability of a fixed dose combination of atorvastatin $10 \mathrm{mg}+$ metformin SR $500 \mathrm{mg}$ in adult Indian patients with diabetic dyslipidaemia. Further, increased dose of atorvastatin was safe in the present case [12]. This was consistent with previous study reporting that atorvastatin initiated at doses of 10,20,40, and $80 \mathrm{mg}$ was effective and safe for the treatment of patients with dyslipidemia. It was further stated that the dose of atorvastatin should depend on the percentage reduction needed to achieve an LDL-C goal, patients with or at risk of coronary heart disease may benefit from starting therapy at a higher dose of atorvastatin[13].

Our results went parallel with earlier reported literature where high-dose statins led to significant reduction in the mean LDL-C levels and in the occurrence of major $\mathrm{CV}$ events (CHD, stroke, revascularizations) in comparison to low-dose statins [14]. In 2006, Shepherd et al., [15] reported high-dose statin monotherapy as safe with no treatment-related adverse events and no elevated levels of liver enzymes.

In developing and poor economic countries including India, there continues to be low medical education and awareness on effective usage of medications prescribed by doctors. The illiterate and poor patients tend to abrupt quit medication or do not stick to the prescribed dosage regimen of the medication leading to suboptimal use and clinical outcome. Hence, these patients remain undertreated for diseases that can be effectively treated. The interpretation of a recent study in patients with rheumatoid arthritis suggested that patients who were not taking their biological drug on the day agreed with their health-care professional had poorer clinical outcomes than those who did take their drug, emphasising the need for strict adherence to biological therapy in patients with this condition [16].

Strict adherence to treatment is essential to avail maximum benefits of therapy. Medication adherence is commonly defined as whether patients take their medications as prescribed (e.g., twice daily), and whether they continue to take a prescribed medication. Medication nonadherence is a growing concern to clinicians, healthcare systems, and other stakeholders (eg, payers) because of mounting evidence that it is prevalent and associated with adverse outcomes and higher costs of care [17]. Medication nonadherence is likely to grow worldwide as patients take more medications to treat chronic conditions and is common for patients with CVDs. Medication adherence potentially leads to increase in hospital visit, duration of hospital stay, suboptimal therapeutic benefit and costs of treatment.

In our study, we observed that due to suboptimal compliance of the patient to the treatment, his LDL-C levels rose from 75 to $85 \mathrm{mg} / \mathrm{dL}$ and the beneficial effects of treatment were abolished. Similar results in terms of higher risk of death, nonfatal MI and loss of beneficial effects of statins with abrupt discontinuation were reported in patients with acute coronary syndrome [18]. Hence, clinicians should underscore benefits of continuing and adhering to the prescribed statin therapy to the patients.

\section{Conclusion}

In conclusion, there continues to be considerable lack of knowledge among people in developing countries on dyslipidemia which can be effectively managed in type 2 diabetes patients by lifehabit modifications in combination with strict adherence to pharmacological interventions. Therefore, there is a need to impart awareness on the dosage, potential side effects, benefits of continuing uninterrupted medication, by clinicians and pharmacists. This would surely translate into effective and optimised management of dyslipidemia which would potentially decrease the occurrence of dyslipidemia in diabetic patients.

\section{Competing Interests}

The authors have declared that no competing interests exist.

\section{References}

1. Mooradian AD, Chehade J, Thurman JE (2002) The role of thiazolidinediones in the treatment of patients with type 2 diabetes mellitus. Treat Endocrinol 1: $13-20$.

2. Farmer JA (2008) Diabetic dyslipidemia and atherosclerosis: evidence from clinical trials. Curr Diab Rep 8: 71-77.

3. Kataokam Y, Uno K, Nicholls SJ (2011) Management of Dyslipidemia in Patients with Diabetes. US Endocrinol 7: 40-45.

4. American Diabetes Association, Bantle JP, Wylie-Rosett J, Albright AL, Apovian CM, et al. (2008) Nutrition recommendations and interventions for diabetes: a position statement of the American Diabetes Association. Diabetes Care 31 Suppl 1: S61-78.

5. National Cholesterol Education Program (NCEP) Expert Panel on Detection, Evaluation, and Treatment of High Blood Cholesterol in Adults (Adult Treatment Panel III) (2002) Third Report of the National Cholesterol Education Program (NCEP) Expert Panel on Detection, Evaluation, and Treatment of High Blood Cholesterol in Adults (Adult Treatment Panel III) final report. Circulation 106: 3143-3421.

6. Look AHEAD Research Group, Pi-Sunyer X, Blackburn G, Brancati FL, Bray GA, et al. (2007) Reduction in weight and cardiovascular disease risk factors in individuals with type 2 diabetes: one-year results of the look AHEAD trial. Diabetes Care 30: 1374-1383.

7. Gaede P, Vedel P, Larsen N, Jensen GV, Parving HH, et al. (2003) Multifactorial intervention and cardiovascular disease in patients with type 2 diabetes. N Engl J Med 348: 383-393.

8. Kim YD, Park KG, Lee YS, Park YY, Kim DK, et al. (2008) Metformin inhibits hepatic gluconeogenesis through AMP-activated protein kinase-dependent regulation of the orphan nuclear receptor SHP. Diabetes 57: 306-314.

9. Rojas LB, Gomes MB (2013) Metformin: an old but still the best treatment for type 2 diabetes. Diabetol Metab Syndr 5: 6 .

10. Save V, Patil N, Moulik N, Rajadhyaksha G (2006) Effect of atorvastatin on type 2 diabetic dyslipidemia. J Cardiovasc Pharmacol Ther 11: 262-270.

11. Diabetes Atorvastin Lipid Intervention (DALI) Study Group (2001) The effect of aggressive versus standard lipid lowering by atorvastatin on diabetic dyslipidemia: the DALI study: a double-blind, randomized, placebocontrolled trial in patients with type 2 diabetes and diabetic dyslipidemia. Diabetes Care 24: 1335-1341.

12. Balasubramanian $R$, Varadharajan $S$, Kathale A, Nagraj LM, Periyandavar I, et al. (2008) Assessment of the efficacy and tolerability of a fixed dose combination of atorvastatin $10 \mathrm{mg}+$ metformin SR $500 \mathrm{mg}$ in diabetic dyslipidaemia in adult Indian patients. J Indian Med Assoc 106: 464-467.

13. Jones PH, McKenney JM, Karalis DG, Downey J (2005) Comparison of the efficacy and safety of atorvastatin initiated at different starting doses in patients with dyslipidemia. Am Heart J 149: e1.

14. LaRosa JC, Grundy SM, Waters DD, Shear C, Barter P, et al. (2005) Intensive lipid lowering with atorvastatin in patients with stable coronary disease. N Engl J Med 352: 1425-1435.

15. Shepherd J, Barter P, Carmena R, Deedwania P, Fruchart JC, et al. (2006) Treating to New Targets Investigators. Effect of lowering LDL-C cholestero substantially below currently recommended levels in patients with coronary heart disease and diabetes: the Treating to New Targets (TNT) study. Diab Care 29: 1220-226. 
Citation: Mahmood D (2015) Management of Dyslipidemia in Type 2 Diabetic Patient: A Case Report. Int J Clin Case Stud 1: 104. doi: http://dx.doi. org/10.15344/2455-2356/2015/104

Page 3 of 3

16. Bluett J, Morgan C, Thurston L, Plant D, Hyrich KL, et al. (2014) Impact of inadequate adherence on response to subcutaneously administered antitumor necrosis factor drugs: results from the Biologics in Rheumatoid Arthritis Genetics and Genomics Study Syndicate cohort. Rheumatology (Oxford); 10. pii: keu358.

17. Ho PM, Bryson CL, Rumsfeld JS (2009) Medication adherence: its importance in cardiovascular outcomes. Circulation 119: 3028-3035.

18. Spencer FA, Fonarow GC, Frederick PD, Wright RS, Every N, et al (2004) Early withdrawal of statin therapy in patients with non-ST-segment elevation myocardial infarction: national registry of myocardial infarction. Arch Intern Med 164: 2162-2168. 